\title{
Antiplatelet resistance and thromboembolic complications in neurointerventional procedures
}

\author{
Thomas J. Oxley ${ }^{1}{ }^{*}$, Richard J. Dowling ${ }^{2}$, Peter J. Mitchell ${ }^{2}$, Stephen Davis ${ }^{1}$ and Bernard Yan ${ }^{1,2}$ * \\ ${ }^{1}$ Department of Neurology, The Royal Melbourne Hospital, Melbourne, VIC, Australia \\ 2 Department of Radiology, The Royal Melbourne Hospital, Melbourne, VIC, Australia
}

\author{
Edited by: \\ Alex Abou-Chebl, University of \\ Louisville School of Medicine, USA \\ Reviewed by: \\ Alex Abou-Chebl, University of \\ Louisville School of Medicine, USA \\ Johanna Fifi, Albert Einstein College \\ of Medicine, USA \\ Marc Lazzaro, Medical College of \\ Wisconsin, USA \\ ${ }^{*}$ Correspondence: \\ Thomas J. Oxley, Department of \\ Neurology, The Royal Melbourne \\ Hospital, Grattan Street Parkville, \\ Melbourne, VIC 3050, Australia. \\ e-mail: tom.oxley@mh.org.au; \\ Bernard Yan, The Royal Melbourne \\ Hospital, Melbourne, VIC 3050, \\ Australia \\ e-mail: bernard.yan@mh.org.au
}

\begin{abstract}
Antiplatelet resistance is emerging as a significant factor in effective secondary stroke prevention. Prevalence of aspirin and clopidogrel resistance is dependent upon laboratory test and remains contentious. Large studies in cardiovascular disease populations have demonstrated worse ischemic outcomes in patients with antiplatelet resistance, particularly in patients with coronary stents. Thromboembolism is a complication of neurointerventional procedures that leads to stroke. Stroke rates related to aneurysm coiling range from 2 to $10 \%$ and may be higher when considering silent ischemia. Stroke associated with carotid stenting is a major cause of morbidity. Antiplatelet use in the periprocedure setting varies among different centers. No guidelines exist for use of antiplatelet regimens in neurointerventional procedures. Incidence of stroke in patients post procedure may be partly explained by resistance to antiplatelet agents. Further research is required to establish the incidence of stroke in patients with antiplatelet resistance undergoing neurointerventional procedures.
\end{abstract}

Keywords: antiplatelet resistance, thromboembolism, endovascular, neurointervention, aspirin, clopidogrel

\section{INTRODUCTION}

The clinical significance of aspirin and clopidogrel resistance is becoming increasingly recognized. Recent large studies have established prevalence in healthy, as well as cardiovascular populations. Prevalence among stroke populations is less well established. Methods for testing resistance have become cheaper, faster, and more accessible at the point-of-care, however validity of these tests remains questionable.

Thromboembolus leading to stroke is a potential complication of neurointerventional procedures. Aneurysm coil embolization, flow diversion stenting, intracranial, and extracranial stenting are associated with low rates thromboembolism that are further reduced with effective antiplatelet management. Practice between interventionalists varies between centers with no established guidelines to guide clinical practice.

The aim of this review was to evaluate incidence of thromboembolus related to neurointerventional procedures, antiplatelet regimens, and the potential impact of resistance to aspirin and clopidogrel in patients undergoing neurointerventional procedures.

\section{ANTIPLATELET RESISTANCE}

Antiplatelet therapy decreases stroke recurrence by $15-20 \%$ (Sandercock et al., 2008). Successful stroke prevention leads to significant reduction in morbidity, mortality, and cost burden to the healthcare system (Holloway et al., 1999). Antiplatelet therapy occurs via inhibition of platelet aggregation. Successful aggregation inhibition lowers the risk of arterial occlusion, with a consequent lower risk of stroke. However, there is emerging evidence that a proportion of the population harbors resistance to antiplatelet therapy.

\section{ASPIRIN RESISTANCE PATHOPHYSIOLOGY AND LABORATORY DIAGNOSIS}

Aspirin inhibits cyclooxygenase 1 (COX 1) preventing the formation of thromboxane A2 (TXA2), a platelet aggregating prostanoid. Laboratory resistance is defined as the failure of aspirin to inhibit platelet thromboxane A2 production or inhibit tests of platelet function that are dependent on platelet TX production (Hankey and Eikelboom, 2006). Multiple assays of platelet function exist but correlate poorly with regard to positive predictive value. Application of the assays in a single population resulted in a variance of diagnosis of aspirin resistance between 4 and 60\% (Lordkipanidzé et al., 2007). The lack of a reproducible, cheap, and accurate test has hampered clinical utility.

The gold standard test is considered to be light transmittance aggregometry (LTA; Harrison, 2005). This test utilizes light transmittance across plasma during platelet aggregation in response to different agonists (ADP, collagen, arachidonic acid). The test is costly, time consuming, operator dependent, and suffers poor reproducibility (Nicholson et al., 1998). One group of tests aims to measure end products of the TX A2 pathway such as serum TX B2 (Hart et al., 2003) and urine 11-dehydroTX B2 (Eikelboom et al., 2002). These metabolites may better reflect the amount of TX A2 derived from sources other than platelets, such as macrophages and monocytes (Mansour et al., 2009). The platelet function analyzer PFA-100 (Dade Behring, Liederbach, Germany) is a point-of-care test that times the formation of a platelet plug in an artificial artery. Aspirin resistance is defined as a closure time $<164 \mathrm{~s}$ despite regular aspirin intake. It is fast and reproducible but expensive, and has failed to demonstrate correlation with clinical outcome (Christiaens et al., 2008). A promising point-of-care test 
is the VerifyNow-Aspirin (Ultegra Rapid Platelet Function Assay, Accumetrics Inc., San Diego, CA, USA). With a cut off value at 550 aspirin reaction units (ARU), the test correlates well with the gold standard LTA, showing good specificity with highly reproducible results (Nielsen et al., 2008).

\section{ASPIRIN RESISTANCE: CLINICAL IMPLICATIONS}

Prevalence of aspirin resistance within the population appears to be between 6 and 27\% (Hovens et al., 2007; Mansour et al., 2009; Shen et al., 2009). The range in prevalence between studies reflects several factors, including use of test. The largest metaanalysis that included 42 studies detected a mean prevalence of 24\% [95\% confidence interval (CI) 20-28\%; Hovens et al., 2007]. When the gold standard LTA was used however, the rate dropped to $6 \%(95 \%$ CI $0-12 \%)$. Use of the point-of-care platelet analyzer detected a prevalence of $26 \%$ (95\% CI $21-31 \%$ ), suggesting that the method of defining aspirin resistance strongly influences estimated prevalence. Interestingly, resistance was shown to be higher in low dose $(\leq 100 \mathrm{mg})$ vs. high dose $(\geq 300 \mathrm{mg})$ populations: [36\% (95\% CI $28-43 \%)$ vs. $19 \%$ (95\% CI $11-$ $26 \%), P=0.0001]$ suggesting a significant dose effect on rates of resistance.

A meta-analysis of a cardiovascular disease population $(n=2930)$ reported a prevalence of $28 \%$ of aspirin resistance that was significantly associated with an increased future risk of ischemic events (Krasopoulos et al., 2008). Other significant clinical associations with aspirin resistance in this type of population have recently been reported as including older age, hypertension, and hyperlipidemia (Beigel et al., 2011).

Similar rates of aspirin resistance in stroke populations have been reported. Harrison et al. (2005) compared prevalence in a population of 100 patients receiving aspirin after TIA or stroke. Prevalence varied depending on test used, with rates of $22 \%$ using the PFA-100, 17\% using the RPFA, and only 5\% using LTA (Harrison et al., 2005). Agreement between the tests was poor. Agreement between the RPFA and LTA $(\kappa=0.16,95 \% \mathrm{CI}$ $0.08-0.39, P=0.11)$, PFA-100 and LTA $(\kappa=0.09$, 95\% CI $0.12-$ $0.30, P=0.32)$ and between the two point-of-care tests $(\kappa=0.14$, $95 \%$ CI $0.08-0.36, \mathrm{P}=0.15$ ) were poor. Only $2 \%$ of patients were aspirin non-responders by all three tests. We previously demonstrated in a stroke population $(n=50)$ that aspirin resistance appeared to occur at a rate of $30 \%$ (Bennett et al., 2008) using the RPFA. This may reflect a higher rate of aspirin resistance in stroke populations compared to healthy populations (Alberts, 2010). The RPFA point-of-care test was recently used in a larger trial of 106 patients. Aspirin resistance in this group recruited at onset of acute stroke was detected in 33\% and was associated with increased short and long term mortality (Ozben et al., 2011).

Poor agreement between tests for aspirin resistance has a significant effect on estimated prevalence rates. Other factors that affect prevalence appear to include aspirin dose and comorbidities. Despite this, lessons from cardiovascular population studies suggest that presence of resistance does significantly predict morbidity in those populations. Large prospective studies are required to demonstrate this in stroke populations. Early evidence suggests that aspirin resistance may be higher in stroke populations.

\section{CLOPIDOGREL RESISTANCE PATHOPHYSIOLOGY AND LABORATORY DIAGNOSIS}

Clopidogrel, a commonly administered antiplatelet, achieves aggregation inhibition by binding to the ADP receptor (P2Y12) expressed on the platelet membrane (Gurbel et al., 2003; O'Donoghue et al., 2009). Clopidogrel is a prodrug ingested in its inactive form, requiring conversion to active form by CYP2C19 superfamily of drug metabolizers (Mega et al., 2009). It exerts its action via active metabolites, which rise proportionally to increasing dose, between 75 and $150 \mathrm{mg}$ (Caplain et al., 1999). A tapering and ceiling effect on platelet aggregation inhibition appears to occur above doses of 400-600 mg (Farid et al., 2010). In vivo studies demonstrate that the conversion to active metabolites requires liver microsomes and NADPH in the presence of a reducing agent (glutathione; Savi et al., 2000). The five CYP forms contributing to formation of active metabolites include CYP3A, CYP2B6, CYP1A2, CYP2C19, and CYP2C9 (Kazui et al., 2010). Only 10\% of the clopidogrel dose is converted into active metabolite (Hagihara et al., 2009).

A hypofunctioning form of CYP2C19 leads to subtherapeutic levels of active clopidogrel (Mega et al., 2009). It has been shown that differing forms of CYP2C19 may account for up to $12 \%$ of clopidogrel "failures" (Shuldiner et al., 2009). In addition, different alleles of the CYP2C19 gene have been identified and their impact on clopidogrel activity further elucidated as: ${ }^{*} 1$ (normal metabolizer), *2 (hypometabolizer), *3 (hypometabolizer), and *17 (hypermetabolizer; Maeda et al., 2011). Carriers of the CYP2C19*2 will exhibit subtherapeutic levels of the active form of clopidogrel due to reduced metabolism of clopidogrel. Of interest, there appears to be a genetic dose effect whereby carriers of *2/*2 (homozygous hypometabolizer) exhibit poorer platelet inhibition compared to carriers of $* 2 /^{*} 1$ (heterozygous hypometabolizer; Maeda et al., 2011).

The potential clinical sequela of CYP2C19*2 carriers is failure in platelet inhibition and significantly increased risks of cardiovascular events and death (Mega et al., 2009). This led to a recent recommendation from FDA in March 2010 requiring physicians to consider alternative antiplatelet therapy to carriers of CYP2C19 non-functioning allele (e.g., CYP2C19*2). Particularly relevant is the finding that CYP2C19*2 (hypometabolizer) and *3 (hypometabolizer) allelic frequencies are 30 and 6.8\%, respectively in Asian patients (Hwang et al., 2011).

Similar to aspirin, methods for diagnosis of clopidogrel resistance are variable however the tests appear to be in better agreement. The gold standard remains LTA. The turbidimetric method employs two-channel aggregometer (Chrono-Log 490 Model, Chrono-Log). Platelet aggregation is assessed within $2 \mathrm{~h}$ of sampling using light transmission. A percent inhibition of aggregation is obtained from calibration by light transmission of platelet rich plasma and platelet poor plasma. A suboptimal or low response to a clopidogrel loading dose was defined when inhibition of 6 AM ADP-induced aggregation $24 \mathrm{~h}$ after clopidogrel administration was $<40 \%$. Similarly, a normal inhibitory response was considered when inhibition of ADP- induced platelet aggregation achieved $>40 \% 24 \mathrm{~h}$ after treatment (Angiolillo et al., 2005). This test was applied in a group of 48 patients undergoing coronary stenting with clopidogrel loading. Forty-eight percent of this group 
were found to have poor platelet aggregation (low responders) in response to clopidogrel loading. Other groups have reported varying rates of resistance using turbidometry in patients post coronary stenting that is at least partly due to varying definitions of resistance. Lau (2004) demonstrated 22\% resistance in 32 patients defining resistance as platelet aggregation inhibition $<10 \%$ following ADP $20 \mu \mathrm{mol} / \mathrm{L}$. Gori et al. (2008) demonstrated lower rates of $6 \%$ using a maximum aggregation rate of $>70 \%$ following $\mathrm{ADP}$ $10 \mu \mathrm{mol} / \mathrm{L}$. This group also looked at dual non-responsiveness (aspirin and clopidogrel) and demonstrated rates of $6 \%$ in their population of 746 patients. Dual non-responsiveness was an independent predictor of drug eluting stent thrombosis [hazard ratio, (HR): 3.18, 95\% CI: 1.14-8.83, $P=0.027]$.

The VerifyNow P2Y12 (Accumetrics Inc., San Diego, CA, USA) is a bedside test that measures the effects of clopidogrel on the P2Y12 receptor. It utilizes a cartridge-based assay to measure platelet function rapidly. Results are expressed as P2Y12 reaction units (PRU) reflecting amount of P2Y12 receptor-mediated aggregation. Percent inhibition is calculated as [ $1-$ PRU/baseline $\mathrm{PRU}) \times 100$ ] reflecting a percent change from baseline aggregation. The estimated baseline result is an independent measurement based on rate and extent of platelet aggregation in the thrombin receptor-activating peptide channel (Malinin et al., 2006), and has been evaluated in several studies (Malinin et al., 2007; Jakubowski et al., 2008). A validation of the VerifyNow P2Y12 assay against the gold standard LTA was conducted in a population of 591 patients. The results indicated that the P2Y12 assay and LTA detected similar patterns of responses to clopidogrel in patients with cardiovascular disease and healthy volunteers. The P2Y12 assay was relatively less sensitive to low and high levels of inhibition but the overall the results were well correlated ( $r \sim 0.7$; Jakubowski et al., 2010).

\section{CLOPIDOGREL RESISTANCE: CLINICAL IMPLICATIONS}

Several recent large studies have attempted to correlate genetic variants in CYP genes and cardiovascular outcomes in patients treated with clopidogrel. Three large studies have demonstrated a significant effect of loss-of-function allele and worse cardiovascular outcomes on clopidogrel. Mega et al. (2009) reported that in carriers of at least one CYP2C19 reduced-function allele had a significantly reduced maximal platelet aggregation response of $9 \%$ points (using LTA in response to $20 \mu \mathrm{mol} / \mathrm{L}$ of ADP) when compared to non-carriers. Carriers had a significantly increased rate of composite outcome (myocardial infarction, stroke, or related death) compared with non-carriers (12.1 vs. 8.0\%; HR for carriers, $1.53 ; 95 \% \mathrm{CI}, 1.07-2.19 ; P=0.01)$. The increase in risk of stent thrombosis was much higher for carriers compared to non-carriers (2.6 vs. $0.8 \%$; HR, 3.09; 95\% CI, $1.19-8.00 ; P=0.02$ ). Collet et al. (2009) investigated a population of 259 young patients ( $<45$ years) using similar outcomes. Loss-of-function carriers taking clopidogrel suffered the composite cardiovascular outcome more often than in non-carriers [ 15 vs. 11 events; HR 3.69 (95\% CI 1.69-8.05), $P=0.0005]$. Again, stent thrombosis was shown to be a greater risk in carrier populations [eight vs. four events; HR 6.02 (1.81$20 \cdot 04), P=0.0009]$ ]. Shuldiner et al. (2009) reported an increased risk of cardiovascular ischemic event or death in patients with a loss-of-function allele (20.9 vs. 10.0\%, HR 2.42; 95\% CI, 1.18-4.99; $P=0.02)$. The loss-of-function allele (CYP2C19*2) was associated with diminished clopidogrel response, accounting for $12 \%$ of the variation in LTA platelet aggregation to $\operatorname{ADP}\left(P=4.3 \times 10^{-11}\right)$. These results were not repeated in a large trial by Paré et al. (2010) involving 5059 patients. The effect of clopidogrel in reducing the rate of cardiovascular events was similar in patients with carriers for loss-of-function alleles and non-carriers [rate among carriers, $8.0 \%$ with clopidogrel vs. $11.6 \%$ with placebo; HR with clopidogrel, 0.69; 95\% CI, 0.49-0.98; rate among non-carriers, 9.5 vs. $13.0 \%$; HR, 0.72; 95\% CI, 0.59-0.87]. The authors suggested the divergent finding was due to differences in rates of coronary stenting. Rates of stenting were $14.5 \%$ in this population compared to $70 \%$ in the three positive trials (Collet et al., 2009; Mega et al., 2009; Shuldiner et al., 2009). They concluded that the greatest use of clopidogrel was in the reduction in the rate of stent thrombosis.

Evidence from large myocardial infarction trials have demonstrated the clinical benefit of addition of clopidogrel to aspirin in achieving superior antiplatelet activity (COMMIT Collaborative Group, 2005; Sabatine et al., 2005; L'Allier et al., 2008). The COMMIT trial of 45,852 patients with acute myocardial infarction investigated the benefit of the addition of clopidogrel to aspirin in patients within $24 \mathrm{~h}$ of onset. Composite primary outcome of death, reinfarction or stroke at discharge was significantly reduced in patients on combination antiplatelet therapy (9.2 vs. $10.1 \%$ $P=0.002$; COMMIT Collaborative Group, 2005). The CLARITYTIMI investigated the benefit of addition of clopidogrel to aspirin within $12 \mathrm{~h}$ of onset of ST elevation myocardial infarction in 3491 patients. Primary composite endpoint of occluded infarct related artery on angiography or death was significantly reduced in the combination antiplatelet agent group 15 vs. $21.7 \% P<0.001$; Sabatine et al., 2005). Authors concluded that the addition of clopidogrel to aspirin improves the patency rate of the infarct related artery and reduces ischemic related complications.

There is scant evidence of the effect of clopidogrel resistance in stroke populations and greater risk for recurrent stroke. Lessons are drawn from large cardiovascular trials that include stroke in composite cardiovascular outcomes. It is likely that clopidogrel resistance exists in stroke populations as it does in the general population (Fukuoka et al., 2011), if not at higher rates. Evidence that resistance is associated with an increased risk for recurrent stroke remains to be seen.

\section{THROMBOEMBOLIC COMPLICATIONS OF NEUROINTERVENTIONAL PROCEDURES ANEURYSM COIL EMBOLIZATION}

Procedure related mortality in endovascular treatment of unruptured aneurysm is around $0.5 \%$ (Lanterna et al., 2004). The most feared and major complication related to mortality is aneurysm rupture and hemorrhage, however the most common complication is thromboembolism leading to stroke (Lanterna et al., 2004). This appears significantly more associated with coiling than clipping (Gerlach et al., 2007). Development of local thrombus formation may involve protrusion of coil loops into the parent artery (Yamada et al., 2007). Thrombus associated with balloon assisted coiling (BAC) relates to stasis associated with balloon inflation and presence of foreign body.

Lanterna et al. (2004) reported a systematic literature review of elective aneurysm embolization complications between 1990 and 
2002. Permanent morbidity rates were reported in 794 patients. When all morbidities were considered, $80 \%$ were due to stroke secondary to thromboembolism. By comparison only $7.5 \%$ were due to hemorrhage. Morbidity decreased from 8.6 to $4.5 \%$ when the average calendar year of treatment was 1995 or later, suggesting an improving technique over time. The authors concluded that prevention and treatment of thromboembolism may be the most effective way to improve clinical outcome with aneurysm embolization.

Other studies have reported rates of thromboembolism in coiling of unruptured aneurysms, ranging from 1.3 to $9.2 \%$ (van Rooij and Sluzewski, 2006; Gerlach et al., 2007; Layton et al., 2007; Yamada et al., 2007; Brooks et al., 2008; Im et al., 2008). The rate of actual infarction is likely higher due to undetected silent infarction. Brooks et al. (2008) demonstrated the rate of stroke during coiling increased to $25 \%$ when using diffusion restriction on MRI DWI routinely post procedure.

No clinical guidelines exist for the management of anticoagulation and antiplatelet agent choice in neurointerventional procedures. According to recommendations (assembled from literature review and survey of expert opinion in 2007) from the World Federation of Interventional and Therapeutic Neuroradiology (WFITN) reduction of thrombotic complication in narrow neck aneurysm is managed by use of heparin intra-procedurally (see Table 1).

Balloon assisted coil embolization (BACE) was described in 1997 as a safe technique for treatment of wide necked aneurysms (Moret et al., 1997). WFITN recommendations include use of aspirin post procedure in this group, but not with pre-procedure loading dose. This remains an area of contention, with use of an antiplatelet loading regimen being center dependent.

Two groups have reported retrospective analyses reviewing thromboembolic complications in aneurysms treated with BAC. One of these groups used pre-procedure antiplatelet loading and the other did not. Sluzewski et al. (2006) compared rates of thromboembolism in aneurysms treated with BACE compared to standard coiling embolization. Both groups were given heparin during the procedure and for $48 \mathrm{~h}$ post procedure. Aspirin was used for 3 months post procedure. The mean aneurysm diameter in the BACE group was significantly wider than the standard coiling group (11.7 vs. $8.3 \mathrm{~mm} P<0.0001) .9 .8 \%$ in the BACE group $(n=71)$ had symptomatic thromboembolism (causing death or disability) compared with $2.2 \%$ in the standard coiling embolization group $(n=756, P<0.0001)$. Layton et al. (2007) report a non-significant difference in thromboembolus risk in 73 patients treated with BACE vs. 148 patients without balloon assistance (14 vs. $9 \% P=0.35$ ), however patients suspected of requiring balloon assistance were treated with loading dual-therapy. It was unclear whether the two groups had a significant difference in size of aneurysm. Of this total population of $221,13(6 \%)$ had symptomatic thromboembolic complications. Twelve of these 13 were not taking pre-procedure antiplatelet medication. None of the patients on clopidogrel alone or on combination clopidogrel and aspirin developed thromboembolic complications. The use of clopidogrel (either alone or combined with aspirin) was the only preprocedural antiplatelet agent that showed a significant difference in local thrombus formation $(P=0.01)$ or symptomatic thromboembolic complication $(P=0.04)$.

Table 1 | Anticoagulation recommendations for neurointerventional procedures.

\begin{tabular}{|c|c|c|c|}
\hline & Intraprocedural anticoagulation & Antiplatelet loading dose & Ongoing antiplatelet treatment \\
\hline Small neck aneurysm coiling & $\begin{array}{l}\text { Heparin bolus of } 5000 \mathrm{U} \text {, then } 1000 \mathrm{U} / \mathrm{l} \\
\text { continuously during the procedure, with } \\
\text { control of ACT ( } \sim 200)\end{array}$ & Nil & Nil \\
\hline Wide neck aneurysm coiling & $\begin{array}{l}\text { Heparin bolus } 5000 \mathrm{U} \text {, then } 1000 \mathrm{U} / \mathrm{l} \\
\text { continuously, with control of ACT } \sim 200\end{array}$ & Nil & $\begin{array}{l}\text { Aspirin } 100 \mathrm{mg} \text { to be continued } \\
\text { indefinitely }\end{array}$ \\
\hline $\begin{array}{l}\text { Aneurysm stenting without } \\
\text { additional coiling }\end{array}$ & $\begin{array}{l}\text { Heparin bolus } 5000 \mathrm{U} \text {, then } 1000 \mathrm{U} / \mathrm{l} \\
\text { continuously, with control of ACT } \sim 200\end{array}$ & $\begin{array}{l}3 \text { days before procedure, aspirin } \\
100 \mathrm{mg} \text { and clopidogrel } 75 \mathrm{mg}\end{array}$ & $\begin{array}{l}\text { Dual-therapy depending on stent-model, } \\
\text { with aspirin to be continued indefinitely } \\
\text { thereafter }\end{array}$ \\
\hline Aneurysm stenting + coiling & $\begin{array}{l}\text { Heparin bolus } 5000 \mathrm{U} \text {, then } 1000 \mathrm{U} / \mathrm{l} \\
\text { continuously, with control of ACT } \sim 200\end{array}$ & $\begin{array}{l}3 \text { days before procedure, aspirin } \\
100 \mathrm{mg} \text { and clopidogrel } 75 \mathrm{mg}\end{array}$ & $\begin{array}{l}\text { Dual-therapy depending on stent-model, } \\
\text { with aspirin to be continued indefinitely } \\
\text { thereafter }\end{array}$ \\
\hline $\begin{array}{l}\text { Aneurysm } \\
\text { balloon-remodeling }\end{array}$ & $\begin{array}{l}\text { Heparin bolus of } 5000 \mathrm{U} \text {, then } 1000 \mathrm{U} / \mathrm{l} \\
\text { continuously during the procedure, with } \\
\text { control of ACT ( } \sim 200)\end{array}$ & Nil & Nil \\
\hline Bare metal stent (BMS) & $\begin{array}{l}\text { Heparin bolus } 5000 \mathrm{U} \text {, then } 1000 \mathrm{U} / \mathrm{l} \\
\text { continuously, with control of ACT } \sim 200\end{array}$ & $\begin{array}{l}3 \text { days before procedure, aspirin } \\
100 \mathrm{mg} \text { and clopidogrel } 75 \mathrm{mg}\end{array}$ & $\begin{array}{l}\text { Dual-therapy for } 3 \text { months, with aspirin to } \\
\text { be continued indefinitely thereafter }\end{array}$ \\
\hline Drug eluting stent (DES) & $\begin{array}{l}\text { Heparin bolus } 5000 \mathrm{U} \text {, then } 1000 \mathrm{U} / \mathrm{l} \\
\text { continuously, with control of ACT } \sim 200\end{array}$ & $\begin{array}{l}3 \text { days before procedure, aspirin } \\
100 \mathrm{mg} \text { and clopidogrel } 75 \mathrm{mg}\end{array}$ & $\begin{array}{l}\text { Dual-therapy for } 1 \text { year, with aspirin to be } \\
\text { continued indefinitely thereafter }\end{array}$ \\
\hline $\begin{array}{l}\text { Embolization of AVM/DAVF } \\
\text { and tumor }\end{array}$ & $\begin{array}{l}\text { Heparin bolus of } 5000 \mathrm{U} \text {, then } 1000 \mathrm{U} / \mathrm{l} \\
\text { continuously during the procedure, with } \\
\text { control of ACT ( } \sim 200)\end{array}$ & Nil & Nil \\
\hline
\end{tabular}

www.wfitn.org 
The coiling procedure potentially posing highest risk for thromboembolism is stent-assisted coiling. This is reflected by standard practice for dual antiplatelet therapy for this group of patients. A 10-center registry recently published a series of 213 consecutively treated aneurysms using stent-assisted coiling (Mocco et al., 2011). In this study with mid term follow-up (median 150 days), nine patients (4\%) patients suffered complications of thrombosis. Two were in the periprocedural setting during stent deployment, while seven (3\%) were delayed thromboembolism. All seven occurred in the setting of cessation of treatment of dual antiplatelet therapy. Interestingly none were associated with coil prolapse into parent vessel.

There is a suggestion that use of an antiplatelet agent prior to coil embolization (both with and without balloon remodeling) appears to have a protective effect against thromboembolism. This hypothesis requires investigation in a randomized prospective trial. The benefit of the antiplatelet agent would need to outweigh the potential increased risk of bleeding complications during coiling. BAC of wide necked aneurysm may be associated with higher rates of thromboembolus and stroke than in narrow necked aneurysms.

\section{FLOW DIVERTING STENTS}

Use of the Pipeline (PED, Chestnut Medical, Menlo Park, CA, USA) or Silk (SFD, Balt Extrusion, Montmorency, France) embolization device to achieve flow diversion in wide necked aneurysms $(>4 \mathrm{~mm})$ with unfavorable dome/neck ratios $(<1.5)$ is becoming widespread. Data is only available from several small trials with short follow-up periods. The first prospective multicenter trial of 31 patients (Nelson et al., 2011) reported two periprocedural strokes $(6.4 \%)$, however one was due to iatrogenic rupture of aneurysm and the other likely attributable to regional coverage of lenticulostriate branches with multiple PEDs. Patients in this trial were managed on dual antiplatelet agents with clopidogrel for a minimum of 30 days and aspirin use for a minimum of 180 days after treatment. Klisch et al. (2011) recently reported two cases of very late thrombosis ( $>1$ year) of PED constructs in posterior circulation aneurysms. Both patients had clopidogrel ceased at 12 months and presented with symptomatic occlusion within 14 days (Klisch et al., 2011). The authors posited that PEDs may remain thrombogenic for longer than conventional intracranial or peripheral bare metal stents and susceptible to very late thrombosis. Walcott et al. (2011) recently reported a review of 10 case series and 190 patients treated with flow diverting stents. Stroke was reported as a complication in $6 \%$ of patients, however perforator stroke was not able to be distinguished from thromboembolic stroke. Use of dual antiplatelet agents was adopted by most groups, with varying continuation rates. Continuing randomized trials are needed to address the question of need for, and ideal regimen, of continuing antiplatelet agents in the setting of insertion of flow diverting stents.

\section{INTRACRANIAL STENTING}

The high risk of stroke related to intracranial arterial stenosis has been well investigated by the WASID trial (Chimowitz et al., 2005). The 2-year rates of ischemic stroke were $19.7 \%$ in 280 patients taking $1300 \mathrm{mg}$ of aspirin with angiographic grade stenosis of
50-99\%. Benefit of self expanding stents over medical therapy remains to be demonstrated in a randomized controlled clinical trial. Two recently published papers report outcomes of patients stented for intracranial stenosis. Fiorella et al. (2011) reported outcomes in 158 patients from five centers with $50-99 \%$ stenosis with a mean follow-up of 14.2 months. Stroke or death occurred in $15.7 \%$, or approximately $13.2 \%$ /year. Seventy-six percent occurred within the first 6 months and none were recorded after 12 months. Eighty-six percent of the postprocedural events were explained by antiplatelet interruption or in-stent restenosis. Of the $27.9 \%$ that were complicated by in-stent restenosis, $80.6 \%$ of these underwent target lesion revascularization. Jiang et al. (2011) recently reported results from a single center prospective Wingspan cohort study. Patients with $>70 \%$ intracranial stenosis were treated with a self expanding stent, and dual antiplatelet therapy for a minimum of 30 days, followed by single agent aspirin $(300 \mathrm{mg})$ or clopidogrel (75 mg). The 1-year risk of outcome events was significantly lower than that in similar WASID patients: $7.3 \%$ (95\% CI, 2.0-12.5\%) vs. $18 \%$ (95\% CI, $13-24 \%$; $P=0.05)$. In-stent restenosis rate was $26.7 \%$ with a majority undergoing target lesion revascularization.

The Stenting and Aggressive Medical Management for Preventing Recurrent stroke in Intracranial Stenosis (SAMMPRIS) trial was recently halted after recruitment of 451 patients due to a 30 day stroke rate of $14 \%$ in the stenting group vs. $5.8 \%$ in the medical arm (National Institute of Neurological Disorders and Stroke Clinical Alert, April 11, 2011) ${ }^{1}$. The anticipated 30-day event rate in the stenting group was $5.2-9.6 \%$ based on data presented by Fiorella et al. (2011) and $10.7 \%$ in the medical arm. The event rate in SAMMPRIS was over double that from the data from Jiang et al. (2011) and Fiorella et al. (2011).

How are these differing results explained? Stenosis related hypoperfusion with tendency to orthostatic cerebral ischemia is less likely to respond to antiplatelet therapy than stenosis causing artery-to-artery thromboembolus and stroke (Abou-Chebl, 2011). Patients with perforator syndromes due to branch origin stenosis rather than due to larger artery stenosis may not be ideal candidates for stenting and should be excluded by imaging (AbouChebl, 2011). Furthermore, testing for effectiveness of platelet aggregation inhibition and resistance of antiplatelet agents was not investigated in these trials. The exact regimen of "best medical therapy" has itself not been elucidated and requires further investigation. Guidelines in antiplatelet therapy in coronary stenting suggest that prolonged dual-therapy is associated with better outcomes than monotherapy (Popma et al., 2004). Further randomized controlled trials are required with appropriate selection of patients most likely to benefit from intracranial stenting over medical therapy alone with appropriate antiplatelet regimens that includes resistance testing.

\section{CAROTID STENTING}

Thromboembolus and stroke is the most common complication associated with carotid stenting.

Rates of periprocedural stroke (within 30 days) were low in the CREST trial (4.1\%; Brott et al., 2010) when compared to the three

${ }^{1}$ http://members.asnr.org/misc/NINDS_Clinical_Alert.pdf 
other major carotid stenting trials: SPACE trial 6.8\% (SPACE Collaborative Group et al., 2006), EVA-3S 9.6\% (Mas et al., 2006), but not ICSS 4.0\% (ICSS Investigators, 2010). There were several confounding factors to explain these differences, including variable inclusion criteria for degrees of stenosis and clinical history of stroke or TIA. Variability in antiplatelet regimens may also explain some of the differences in stroke post procedure.

The CREST trial pre-procedure loading involved $48 \mathrm{~h}$ of $325 \mathrm{mg}$ aspirin twice daily and $75 \mathrm{mg}$ clopidogrel twice daily. When the procedure was scheduled within $48 \mathrm{~h}$ a more rapid loading regimen involved $650 \mathrm{mg}$ of aspirin and $450 \mathrm{mg}$ of clopidogrel at least $4 \mathrm{~h}$ before the procedure. Post procedure regimens involved dual-therapy for 4 weeks with $75 \mathrm{mg}$ of clopidogrel and one or two $325 \mathrm{mg}$ doses of aspirin daily. Single agent therapy was used after 4 weeks. This regimen was more aggressive than other trials that had higher rates of stroke. Rates of stroke were double that of the CREST trial in the EVA-3S trial (9.6\%). The dosing for pre-procedure loading involved aspirin between 100 and $300 \mathrm{mg}$ daily as well as clopidogrel $75 \mathrm{mg}$ daily for 3 days. The post procedure regimen was similar. However antiplatelet compliance rates in EVA-3S were poor. Seventeen percent of patients were not on dual antiplatelet medications prior to procedure and $15 \%$ were not compliant post procedure (Gupta et al., 2010). The SPACE trial with rates of stroke at $6.8 \%$ had a similar regimen to the EVA$3 \mathrm{~S}$ trial: $100 \mathrm{mg}$ of aspirin daily and $75 \mathrm{mg}$ of clopidogrel daily for 3 days pre-procedure and at least 1 month post procedure. Adherences to the pre-procedure loading also varied between trials, with 97.7\% adherence in CREST, vs. $82.9 \%$ in EVA-3S. No studies of platelet function were pursued in these trials to assess effectiveness of platelet inhibition prior to procedure. Variability amongst dosing regimen may in part explain differences in stroke rates between trials.

A meta-analysis of 3433 patients from the EVA-3S, SPACE, and ICSS trials published in The Lancet 2010 (Collaboration, 2010) reported that the greater morbidity related to stenting over endarterectomy correlated with age. Patients over the age of 70 had a significantly higher risk of 30-day stroke with stenting compared to endarterectomy ( 10.5 vs. $4.4 \%, P=0.0078$ ). Patients below age of 70 did not have a significant difference between groups (5.1 vs. $4.5 \%)$. The study reported a linear increase of the risk ratio between stenting and endarterectomy with age. The authors concluded that a biological mechanism might be mediating the association. General burden of atherosclerosis of the aortic arch, increased plaque instability, altered configuration of the aortic arch, or vessel tortuosity were raised as possibilities. Interventionalist (compared to surgeon) experience has also been raised as a significant factor that may in part explain the disparity of rates of stroke complication between the carotid stenting RCTs (Gupta et al., 2010).

\section{IMPLICATIONS FOR NEUROINTERVENTION PRACTICE}

The WFITN ${ }^{2}$ has acknowledged the lack of consensus guidelines for antiplatelet therapy in the periprocedural setting. Their website recommendations were compiled from consensus expert opinion

\footnotetext{
${ }^{2}$ www.wfitn.org
}

in 2007 but have not been formally published. The recommendations were released in an effort to spark a debate over appropriate guidelines. As yet, no such guidelines exist.

Pandya et al. (2010) recently reported the largest prospective trial to evaluate pre-procedure dosing regimens and antiplatelet resistance in neurointerventional procedures. Data was collected from 216 consecutive patients including all neurointerventional procedures. Thirteen percent of patients taking aspirin were found to be resistant ( $>550$ ARU) while $66 \%$ of patients taking clopidogrel were resistant ( $<50 \%$ inhibition of P2Y12/ADP receptor). Patients taking clopidogrel $75 \mathrm{mg}$ for $\geq 7$ days, $300 \mathrm{mg}$ for $24 \mathrm{~h}$, and $600 \mathrm{mg}$ same day load had a mean P2Y12/ADP inhibition of $45 \%$, $35 \%(P=0.09)$, and $16 \%$, respectively $(P=0.005)$. The authors suggested this data may reflect an inferiority with same day loading when compared to longer loading periods to achieve adequate platelet inhibition.

Lee et al. (2008) applied point-of-care tests to assess antiplatelet response prior to neurointerventional procedures. One-hundred six consecutive patients were assessed in a single center from 2006 to 2007. Antiplatelet regimen included aspirin ( $325 \mathrm{mg}$ daily) and clopidogrel ( $75 \mathrm{mg}$ for $5-10$ days pre-procedure). Two percent of patients demonstrated aspirin poor response ( $<550 \mathrm{ARU})$ and $42.9 \%$ of patients demonstrated clopidogrel poor response ( $>40 \%$ inhibition). Three cases were complicated by intraprocedural thrombosis, with all three cases observed in the poor responders group. The authors commented that frequency of poor responders appears high in a population undergoing neurointerventional procedures. Routine monitoring with point-of-care tests may be helpful for early identification of non-responders.

Prabhakaran et al. (2008) conducted a similar single center prospective evaluation in 76 patients undergoing cerebrovascular stenting. Aspirin resistance was detected in $4.2 \%$ of patients (ARU > 550) and clopidogrel resistance in $51.9 \%$ of patients ( $>40 \%$ inhibition). Outcomes were not assessed in relation to rates of resistance in this group. Interestingly, a significant inverse relationship was demonstrated between dose of aspirin and rate of resistance, with lower weekly doses of aspirin correlating to higher rates of resistance $(r=-0.31, P=0.01)$. The authors highlighted the need for further investigation of ideal dosing, timing and duration of antiplatelet therapy for neurointerventional stent procedures.

The existence of aspirin and clopidogrel resistance appears certain. Less clear is the true prevalence and appears dependent on factors including choice of test, dose of antiplatelet agent, age of patient, and presence of comorbidities including hypertension and hyperlipidemia. The use of point-of-care tests such as the VerifyNow RPFA and P2Y12 enable rapid testing and may assist in clinical decision making but more data are needed for validation. In assessing platelet function, the P2Y12 is well correlated to LTA, which has been shown in large trials to be associated with lossof-function genetic CYP2C19 expression and significantly poorer cardiovascular outcomes in patients taking clopidogrel. It is likely, but not yet tested, that similar associations with stroke will exist in populations that undergo neurointerventional procedures. The most significant impact on future risk of ischemic event in poor responders to clopidogrel was detected in patients with a history of coronary stenting. Whether similar conclusions can be drawn for 
patients with intracranial or extracranial stents remains to be seen. Use of point-of-care tests in patients undergoing carotid stenting has been described (Maruyama et al., 2011), with addition of an extra agent showing improved platelet aggregation inhibition.

A risk of thromboembolism exists in coiling procedures. Stroke associated with coiling occurs in between 2 and $9 \%$ of patients despite antiplatelet therapy, and may be as high as $25 \%$ when considering silent ischemia on MRI diffusion restriction. There is a suggestion that antiplatelet agents may reduce the risk of thromboembolism without increasing the risk of hemorrhage, but this question needs to be studied in a prospective trial. Risk of thromboembolism may increase with wide necked aneurysms. The increased prevalence of antiplatelet resistance in older populations that have increased comorbidities should be taken into account when pursuing neurointerventional procedures in this group. Poorer outcomes in carotid stenting may be

\section{REFERENCES}

Abou-Chebl, A. (2011). Intracranial stenting with wingspan: still awaiting a safe landing. Stroke 42, 1809-1811.

Alberts, M. J. (2010). Platelet function testing for aspirin resistance is reasonable to do: yes! Stroke 41, 2400-2401.

Angiolillo, D. J., Fernandez-Ortiz, A., Bernardo, E., Ramírez, C., BarreraRamirez, C., Sabaté, M., Hernández, R., Moreno, R., Escaned, J., Alfonso, F., Bañuelos, C., Costa, M. A., Bass, T. A., and Macaya, C. (2005). Identification of low responders to a 300-mg clopidogrel loading dose in patients undergoing coronary stenting. Thromb Res. 115, 101-108.

Beigel, R., Hod, H., Fefer, P., Asher, E., Novikov, I., Shenkman, B., Savion, N., Varon, D., and Matetzky, S. (2011). Relation of aspirin failure to clinical outcome and to platelet response to aspirin in patients with acute myocardial infarction. Am. J. Cardiol. 107, 339-342.

Bennett, D., Yan, B., Macgregor, L., Eccleston, D., and Davis, S. M. (2008). A pilot study of resistance to aspirin in stroke patients. J. Clin. Neurosci. 15, 1204-1209.

Brooks, N. P., Turk, A. S., Niemann, D. B., Aagaard-Kienitz, B., Pulfer, K., and Cook, T. (2008). Frequency of thromboembolic events associated with endovascular aneurysm treatment: retrospective case series. $J$. Neurosurg. 108, 1095-1100.

Brott, T. G., Hobson, R. W., Howard, G., Roubin, G. S., Clark, W. M., Brooks, W., Mackey, A., Hill, M. D., Leimgruber, P. P., Sheffet, A. J., Howard, V. J., Moore, W. S., Voeks, J. H., Hopkins, L. N., Cutlip, D. E., Cohen, D. J., Popma, J. J., Ferguson, R. D., Cohen, S. N., Blackshear, J. L., Silver, F. L.,
Mohr, J. P., Lal, B. K., Meschia, J. F., and CREST Investigators. (2010). Stenting versus endarterectomy for treatment of carotid-artery stenosis. N. Engl. J. Med. 363, 11-23.

Caplain, H., Donat, F., Gaud, C., and Necciari, J. (1999). Pharmacokinetics of clopidogrel. Semin. Thromb. Hemost. 25(Suppl. 2), 25-28.

Chimowitz, M. I., Lynn, M. J., HowlettSmith, H., Stern, B. J., Hertzberg, V. S., Frankel, M. R., Levine, S. R., Chaturvedi, S., Kasner, S. E., Benesch, C. G., Sila, C. A., Jovin, T. G., Romano, J. G., and WarfarinAspirin Symptomatic Intracranial Disease Trial Investigators. (2005). Comparison of warfarin and aspirin for symptomatic intracranial arterial stenosis. N. Engl. J. Med. 352, 1305-1316.

Christiaens, L., Ragot, S., Mergy, J., Allal, J., and Macchi, L. (2008). Major clinical vascular events and aspirinresistance status as determined by the PFA-100 method among patients with stable coronary artery disease: a prospective study. Blood Coagul. Fibrinolysis 19, 235-239.

Collaboration, C. S. T. (2010). Shortterm outcome after stenting versus endarterectomy for symptomatic carotid stenosis: a preplanned metaanalysis of individual patient data. Lancet 376, 1062-1073.

Collet, J.-P., Hulot, J.-S., Pena, A., Villard, E., Esteve, J.-B., Silvain, J., Payot, L., Brugier, D., Cayla, G., Beygui, F., Bensimon, G., Funck-Brentano, C., and Montalescot, G. (2009). Cytochrome P450 2C19 polymorphism in young patients treated with clopidogrel after myocardial infarction: a cohort study. Lancet 373, 309-317.

COMMIT Collaborative Group. (2005). Addition of clopidogrel to aspirin

related to increased rates of antiplatelet resistance in this group and requires further investigation. Point-of-care testing in these groups may be warranted. Meta-analysis evidence provides support that higher doses of aspirin lead to lower levels of resistance. This may be a treatment option in patients shown to have aspirin resistance.

\section{RECOMMENDATION}

Effective antiplatelet therapy reduces complications associated with neurointerventional procedures. Point-of-care tests to assess response to aspirin and clopidogrel are available but require further validation. Pre-procedure loading with antiplatelet agents may be more effective over 7 days than more rapid regimens. Titration of dosing or addition of second antiplatelet agent following diagnosis of resistance may be reasonable but has not been prospectively investigated.

in 45852 patients with acute myocardial infarction: randomised placebo-controlled trial. Lancet 366, 1607-1621.

Eikelboom, J. W., Hirsh, J., Weitz, J. I., Johnston, M., Yi, Q., and Yusuf, S. (2002). Aspirin-resistant thromboxane biosynthesis and the risk of myocardial infarction, stroke, or cardiovascular death in patients at high risk for cardiovascular events. Circulation 105, 1650-1655.

Farid, N. A., Kurihara, A., and Wrighton, S. A. (2010). Metabolism and disposition of the thienopyridine antiplatelet drugs ticlopidine, clopidogrel, and prasugrel in humans. $J$. Clin. Pharmacol. 50, 126-142.

Fiorella, D. J., Turk, A. S., Levy, E. I., Pride, G. L., Woo, H. H., Albuquerque, F. C., Welch, B. G., Niemann, D. B., Aagaard-Kienitz, B., Rasmussen, P. A., Hopkins, L. N., Masaryk, T. J., and McDougall, C. G. (2011). U.S. Wingspan Registry: 12month follow-up results. Stroke 42, 1976-1981.

Fukuoka, T., Furuya, D., Takeda, H., Dembo, T., Nagoya, H., Kato, Y., Deguchi, I., Maruyama, H., Horiuchi, Y., and Tanahashi, N. (2011) Evaluation of clopidogrel resistance in ischemic stroke patients. Intern. Med. 50, 31-35.

Gerlach, R., Beck, J., Setzer, M., Vatter, H., Berkefeld, J., Mesnil De Rochemont Du, R., Raabe, A., and Seifert, V. (2007) Treatment related morbidity of unruptured intracranial aneurysms: results of a prospective single centre series with an interdisciplinary approach over a 6 year period (1999-2005). J. Neurol. Neurosurg. Psychiatry 78, 864-871.

Gori, A. M., Marcucci, R., Migliorini, A., Valenti, R., Moschi, G., Paniccia, R., Buonamici, P., Gensini, G. F.,
Vergara, R., Abbate, R., and Antoniucci, D. (2008). Incidence and clinical impact of dual nonresponsiveness to aspirin and clopidogrel in patients with drug-eluting stents. $J$. Am. Coll. Cardiol. 52, 734-739.

Gupta, R., Jovin, T. G., Yavagal, D., and Abou-Chebl, A. (2010). Carotid endarterectomy vs. carotid stenting: fairly comparable or unfairly compared? Front. Neurol. 1:14. doi:10.3389/fneur.2010.00014

Gurbel, P. A., Bliden, K. P., Hiatt, B. L., and O'Connor, C. M. (2003). Clopidogrel for coronary stenting: response variability, drug resistance, and the effect of pretreatment platelet reactivity. Circulation 107, 2908-2913.

Hagihara, K., Kazui, M., Kurihara, A., Yoshiike, M., Honda, K., Okazaki, O., Farid, N. A., and Ikeda, T. (2009). A possible mechanism for the differences in efficiency and variability of active metabolite formation from thienopyridine antiplatelet agents, prasugrel and clopidogrel. Drug Metab. Dispos. 37, 2145-2152.

Hankey, G. J., and Eikelboom, J. W. (2006). Aspirin resistance. Lancet 367, 606-617.

Harrison, P. (2005). Platelet function analysis. Blood Rev. 19, 111-123.

Harrison, P., Segal, H., Blasbery, K., Furtado, C., Silver, L., and Rothwell, P. M. (2005). Screening for aspirin responsiveness after transient ischemic attack and stroke: comparison of 2 point-of-care platelet function tests with optical aggregometry. Stroke 36, 1001-1005.

Hart, R. G., Leonard, A. D., Talbert, R. L., Pearce, L. A., Cornell, E., Bovill, E., and Feinberg, W. M. (2003). Aspirin dosage and thromboxane synthesis in patients with vascular disease. Pharmacotherapy 23, 579-584. 
Holloway, R. G., Benesch, C. G., Rahilly, C. R., and Courtright, C. E. (1999). A systematic review of cost-effectiveness research of stroke evaluation and treatment. Stroke 30, 1340-1349.

Hovens, M. M. C., Snoep, J. D., Eikenboom, J. C. J., van der Bom, J. G., Mertens, B. J. A., and Huisman, M. V. (2007). Prevalence of persistent platelet reactivity despite use of aspirin: a systematic review. Am. Heart J. 153, 175-181.

Hwang, S.-J., Jeong, Y.-H., Kim, I.-S., Koh, J.-S., Kang, M.-K., Park, Y., Kwak, C. H., and Hwang, J. Y. (2011). The cytochrome $2 \mathrm{C} 19^{*} 2$ and $* 3$ alleles attenuate response to clopidogrel similarly in East Asian patients undergoing elective percutaneous coronary intervention. Thromb Res. 127, 23-28.

ICSS Investigators. (2010). Carotid artery stenting compared with endarterectomy in patients with symptomatic carotid stenosis (International Carotid Stenting Study): an interim analysis of a randomised controlled trial. Lancet 375, 985-997.

Im, S.-H., Han, M., Kwon, O.-K., Kwon, B., Kim, S., Kim, J., and Oh, C. W. (2008). Endovascular coil embolization of 435 small asymptomatic unruptured intracranial aneurysms: procedural morbidity and patient outcome. AJNR Am. J. Neuroradiol. $30,79-84$

Jakubowski, J. A., Li, Y. G., Small, D. S., Payne, C. D., Tomlin, M. E., Luo, J., and Winters, K. J. (2010). A comparison of the VerifyNow P2Y12 point-of-care device and light transmission aggregometry to monitor platelet function with prasugrel and clopidogrel: an integrated analysis. J. Cardiovasc. Pharmacol. 56, 29-37.

Jakubowski, J. A., Payne, C. D., Li, Y. G., Brandt, J. T., Small, D. S., Farid, N. A., Salazar, D. E., and Winters, K. J. (2008). The use of the VerifyNow P2Y12 point-of-care device to monitor platelet function across a range of P2Y12 inhibition levels following prasugrel and clopidogrel administration. Thromb Haemost. 99, 409-415.

Jiang, W.-J., Yu, W., Du, B., Gao, F., and Cui, L.-Y. (2011). Outcome of patients with $>=70 \%$ symptomatic intracranial stenosis after wingspan stenting. Stroke 42, 1971-1975.

Kazui, M., Nishiya, Y., Ishizuka, T., Hagihara, K., Farid, N. A., Okazaki, O., Ikeda, T., and Kurihara, A. (2010). Identification of the human cytochrome P450 enzymes involved in the two oxidative steps in the bioactivation of clopidogrel to its pharmacologically active metabolite. Drug Metab. Dispos. 38, 92-99.

Klisch, J., Turk, A., Turner, R., Woo, H. H., and Fiorella, D. (2011). Very late thrombosis of flow-diverting constructs after the treatment of large fusiform posterior circulation aneurysms. AJNR Am. J. Neuroradiol. 32, 627-632.

Krasopoulos, G., Brister, S. J., Beattie, W. S., and Buchanan, M. R. (2008). Aspirin "resistance" and risk of cardiovascular morbidity: systematic review and meta-analysis. BMJ 336, 195-198.

L'Allier, P. L., Ducrocq, G., Pranno, N., Noble, S., Ibrahim, R., Grégoire, J. C., Azzari, F., Nozza, A., Berry, C., Doucet, S., Labarthe, B., Théroux, P., Tardif, J. C., and PREPAIR Study Investigators. (2008). Clopidogrel 600-mg double loading dose achieves stronger platelet inhibition than conventional regimens: results from the PREPAIR randomized study. J. Am. Coll. Cardiol. 51, 1066-1072.

Lanterna, L. A., Tredici, G., Dimitrov, B. D., and Biroli, F. (2004). Treatment of unruptured cerebral aneurysms by embolization with guglielmi detachable coils: casefatality, morbidity, and effectiveness in preventing bleeding - a systematic review of the literature. Neurosurgery 55, 767-778.

Lau, W. C. (2004). Contribution of hepatic cytochrome P450 3A4 metabolic activity to the phenomenon of clopidogrel resistance. Circulation 109, 166-171.

Layton, K., Cloft, H., Gray, L., Lewis, D., and Kallmes, D. (2007). Balloon-assisted coiling of intracranial aneurysms: evaluation of local thrombus formation and symptomatic thromboembolic complications. AJNR Am. J. Neuroradiol. 28, 1172-1175.

Lee, D., Arat, A., Morsi, H., Shaltoni, H., Harris, J., and Mawad, M. (2008). Dual antiplatelet therapy monitoring for neurointerventional procedures using a point-of-care platelet function test: a single-center experience. AJNR Am. J. Neuroradiol. 29, 1389-1394.

Lordkipanidzé, M., Pharand, C., Schampaert, E., Turgeon, J., Palisaitis, D. A., and Diodati, J. G. (2007). A comparison of six major platelet function tests to determine the prevalence of aspirin resistance in patients with stable coronary artery disease. Eur. Heart J. 28, 1702-1708.

Maeda, A., Ando, H., Asai, T., Ishiguro, H., Umemoto, N., Ohta, M., Morishima, M., Sumida, A., Kobayashi, T., Hosohata, K., Ushijima, K., and Fujimura, A. (2011). Differential impacts of CYP2C19 gene polymorphisms on the antiplatelet effects of clopidogrel and ticlopidine. Clin. Pharmacol. Ther. 89, 229-233.

Malinin, A., Pokov, A., Spergling, M. Defranco, A., Schwartz, K., Schwartz, D., Mahmud, E., Atar, D., and Serebruany, V. (2007). Monitoring platelet inhibition after clopidogrel with the VerifyNow-P2Y12(R) rapid analyzer: the verify thrombosis risk assessment (VERITAS) study. Thromb Res. 119, 277-284.

Malinin, A., Pokov, A., Swaim, L., Kotob, M., and Serebruany, V. (2006). Validation of a VerifyNow-P2Y12 cartridge for monitoring platelet inhibition with clopidogrel. Methods Find Exp. Clin. Pharmacol. 28, 315-322.

Mansour, K., Taher, A. T., Musallam, K. M., and Alam, S. (2009). Aspirin resistance. Adv. Hematol. 2009, 937352.

Maruyama, H., Takeda, H., Dembo, T., Nagoya, H., Kato, Y., Fukuoka, T., Deguchi, I., Horiuchi, Y., and Tanahashi, N. (2011). Clopidogrel resistance and the effect of combination cilostazol in patients with ischemic stroke or carotid artery stenting using the VerifyNow P2Y12 Assay. Intern. Med. 50, 695-698.

Mas, J.-L., Chatellier, G., Beyssen, B., Branchereau, A., Moulin, T., Becquemin, J.-P., Larrue, V., Lièvre, M., Leys, D., Bonneville, J. F., Watelet, J., Pruvo, J. P., Albucher, J. F., Viguier, A., Piquet, P., Garnier, P., Viader, F., Touzé, E., Giroud, M., Hosseini, H., Pillet, J. C., Favrole, P., Neau, J. P., Ducrocq, X., and EVA-3S Investigators. (2006). Endarterectomy versus stenting in patients with symptomatic severe carotid stenosis. $N$. Engl. J. Med. 355, 1660-1671.

Mega, J. L., Close, S. L., Wiviott, S. D., Shen, L., Hockett, R. D., Brandt, J. T., Walker, J. R., Antman, E. M., Macias, W., Braunwald, E., and Sabatine, M. S. (2009). Cytochrome p450 polymorphisms and response to clopidogrel. N. Engl. J. Med. 360, 354-362.

Mocco, J., Fargen, K. M., Albuquerque, F. C., Bendok, B. R., Boulos, A. S., Carpenter, J. S., Fiorella, D. J., Hoh, B. L., Howington, J. U., Liebman, K. M., Natarajan, S. K., Rai, A. T. Rodriguez-Mercado, R., Siddiqui, A. H., Snyder, K. V., Veznedaroglu, E., Hopkins, L. N., and Levy, E. I. (2011). Delayed thrombosis or stenosis following enterprise-assisted stentcoiling: is it safe? Midterm results of the interstate collaboration of enterprise stent coiling. Neurosurgery 69, 908-913.

Moret, J., Cognard, C., Weill, A., Castaings, L., and Rey, A. (1997). Reconstruction technic in the treatment of wide-neck intracranial aneurysms. Long-term angiographic and clinical results. Apropos of 56 cases. J. Neuroradiol. 24, 30-44.

Nelson, P. K., Lylyk, P., Szikora, I., Wetzel, S. G., Wanke, I., and Fiorella, D. (2011). The pipeline embolization device for the intracranial treatment of aneurysms trial. AJNR Am. J. Neuroradiol. 32, 34-40.

Nicholson, N. S., Panzer-Knodle, S. G., Haas, N. F., Taite, B. B., Szalony, J. A., Page, J. D., Feigen, L. P., Lansky, D. M., and Salyers, A. K. (1998). Assessment of platelet function assays. Am. Heart J. 135, S170-S178.

Nielsen, H. L., Kristensen, S. D., Thygesen, S. S., Mortensen, J., Pedersen S. B., Grove, E. L., and Hvas, A. M. (2008). Aspirin response evaluated by the VerifyNow Aspirin System and light transmission aggregometry. Thromb Res. 123, 267-273.

O’Donoghue, M. L., Braunwald, E., Antman, E. M., Murphy, S. A., Bates E. R., Rozenman, Y., Michelson, A. D., Hautvast, R. W., Ver Lee, P. N., Close, S. L., Shen, L., Mega, J. L., Sabatine, M. S., and Wiviott, S. D. (2009). Pharmacodynamic effect and clinical efficacy of clopidogrel and prasugrel with or without a proton-pump inhibitor: an analysis of two randomised trials. Lancet 374, 989-997.

Ozben, S., Ozben, B., Tanrikulu, A M., Ozer, F., and Ozben, T. (2011). Aspirin resistance in patients with acute ischemic stroke. J. Neurol. 258, 1979-1986.

Pandya, D. J., Fitzsimmons, B. F. M., Wolfe, T. J., Hussain, S. I., Lynch, J. R., Ortega-Gutierrez, S., and Zaidat, O. O. (2010). Measurement of antiplatelet inhibition during neurointerventional procedures: the effect of antithrombotic duration and loading dose. J. Neuroimaging 20, 64-69.

Paré, G., Mehta, S. R., Yusuf, S., Anand, S. S., Connolly, S. J., Hirsh, J., Simonsen, K., Bhatt, D. L., Fox, K. A., and Eikelboom, J. W. (2010). Effects of CYP2C19 genotype on outcomes of clopidogrel treatment. N. Engl. J. Med. 363, 1704-1714.

Popma, J. J., Berger, P., Ohman, E. M., Harrington, R. A., Grines, C., and Weitz, J. I. (2004) Antithrombotic therapy during percutaneous coronary intervention: the Seventh ACCP Conference on Antithrombotic and Thrombolytic Therapy. Chest 126(Suppl. 3), 576S-599S.

Prabhakaran, S., Wells, K. R., Lee, V. H., Flaherty, C. A., and Lopes, D. K. (2008). Prevalence and risk factors for aspirin and clopidogrel resistance in cerebrovascular stenting. AJNR Am. J. Neuroradiol. 29, 281-285. 
Sabatine, M. S., Cannon, C. P., Gibson, C. M., López-Sendón, J. L., Montalescot, G., Theroux, P., Claeys, M. J., Cools, F., Hill, K. A., Skene, A. M., McCabe, C. H., Braunwald, E., and CLARITY-TIMI 28 Investigators. (2005). Addition of clopidogrel to aspirin and fibrinolytic therapy for myocardial infarction with STsegment elevation. N. Engl. J. Med. 352, 1179-1189.

Sandercock, P. A. G., Counsell, C., Gubitz, G. J., and Tseng, M.C. (2008). Antiplatelet therapy for acute ischaemic stroke. Cochrane Database Syst. Rev. CD000029.

Savi, P., Pereillo, J. M., Uzabiaga, M. F., Combalbert, J., Picard, C., Maffrand, J. P., Pascal, M., and Herbert, J. M. (2000). Identification and biological activity of the active metabolite of clopidogrel. Thromb. Haemost. 84, 891-896.

Shen, H., Herzog, W., Drolet, M., Pakyz, R., Newcomer, S., Sack, P., Karon, H., Ryan, K. A., Zhao, Y., Shi, X., Mitchell, B. D., and Shuldiner, A. R. (2009). Aspirin Resistance in healthy drug-naive men versus women (from the Heredity and Phenotype Intervention Heart Study). Am. J. Cardiol. 104, 606-612.

Shuldiner, A. R., O'Connell, J. R., Bliden, K. P., Gandhi, A., Ryan, K., Horenstein, R. B., Damcott, C. M., Pakyz, R., Tantry, U. S., Gibson, Q., Pollin, T. I., Post, W., Parsa, A., Mitchell, B. D., Faraday, N., Herzog, W., and Gurbel, P. A. (2009). Association of cytochrome P450 2C19 genotype with the antiplatelet effect and clinical efficacy of clopidogrel therapy. JAMA 302, 849-857.

Sluzewski, M., van Rooij, W. J., Beute, G. N., and Nijssen, P. C. (2006). Balloon-assisted coil embolization of intracranial aneurysms: incidence, complications, and angiography results. J. Neurosurg. 105, 396-399.

SPACE Collaborative Group, Ringleb, P. A., Allenberg, J., Brückmann, H., Eckstein, H.-H., Fraedrich, G., Hartmann, M., Hennerici, M., Jansen, O., Klein, G., Kunze, A., Marx, P., Niederkorn, K., Schmiedt, W.,
Solymosi, L., Stingele, R., Zeumer, H., and Hacke, W. (2006). 30 day results from the SPACE trial of stent-protected angioplasty versus carotid endarterectomy in symptomatic patients: a randomised non-inferiority trial. Lancet 368, 1239-1247.

van Rooij, W. J., and Sluzewski, M. (2006). Procedural morbidity and mortality of elective coil treatment of unruptured intracranial aneurysms. AJNR Am. J. Neuroradiol. 27, 1678-1680.

Walcott, B. P., Pisapia, J. M., Nahed, B. V., Kahle, K. T., and Ogilvy, C. S. (2011). Early experience with flow diverting endoluminal stents for the treatment of intracranial aneurysms. J. Clin. Neurosci. 18, 891-894.

Yamada, N., Cross, D., Pilgram, T., Moran, C., Derdeyn, C. and Dacey, R. (2007). Effect of antiplatelet therapy on thromboembolic complications of elective coil embolization of cerebral aneurysms. AJNR Am. J. Neuroradiol. 28 , 1778-1782.
Conflict of Interest Statement: The authors declare that the research was conducted in the absence of any commercial or financial relationships that could be construed as a potential conflict of interest.

Received: 25 July 2011; paper pending published: 14 September 2011; accepted: 30 November 2011; published online: 26 December 2011.

Citation: Oxley TJ, Dowling RJ, Mitchell PJ, Davis $S$ and Yan B (2011) Antiplatelet resistance and thromboembolic complications in neurointerventional procedures. Front. Neur. 2:83. doi: 10.3389/fneur.2011.00083

This article was submitted to Frontiers in Endovascular and Interventional Neurology, a specialty of Frontiers in Neurology. Copyright (c) 2011 Oxley, Dowling, Mitchell, Davis and Yan. This is an open-access article distributed under the terms of the Creative Commons Attribution Non Commercial License, which permits non-commercial use, distribution, and reproduction in other forums, provided the original authors and source are credited. 